only liquid diet-strong beef-tea, eggs, milk \&c.-for a week or ten days before the operation. The bowels should be kept well opened for some three or four days before by castor oil or some saline aperient, and the rectum washed out as far as possible once a day with warm water enemata.

Operation. - The abdomen being opened by a straight incision in the usual position, a small flat sponge with a long string attached to it is passed into the cavity to keep the small intestines and omentum from protruding; the index finger of the left hand is then passed backwards along the brim of the pelvis until it reacbes the sacro-iliac synchondrosis, when the descending colon will usually be felt dipping into the pelvis ; the finger is then passed over the colon, and a portion of the sigmoid flexure hooked up into the wound, and a loop some inches long withdrawn through the opening. A band of indiarubber is now to be passed through the mesocolon and fastened tolerably firmly round the intestine as high up as possible, to prevent the passage of its contents when the intestine is divided. The wound is next packed with small sponges, to each of which a long string should be attached, and the loop of intestine is surrounded with cotton-wool pads soaked in warn and carbolised water. The intestine is now cut across with scissors about three inches from its upper end, and the contents, if any, evacuated, in some cases it will be desirable to wash the rut out with warm carbolised water. All bleeding points being secured, the divided end of the lower segment is to be invaginated into itself and the end closed by a continuous catgut suture passing through its serous and muscular coats. The mesocolon may now be torn downwards for an inch or more if necessary, and the torn edges stitched over with fine catgut suture. This portion of the flexure is then allowed to drop back into the abdominal cavity. The divided end of the upper portion of intestine is next inwaginated and secured in place by means of a continuous catgut suture and the indiarubber band removed. All sponges and wool-packing can now be removed and the parts thoroughly washed, and the parietal wound closed in the usual manner, care, however, being taken that the suture just above the intestine should pass through its serous and muscular coats, and the suture below is passed through the meso-colon. Two fine silk sutures are to be passed through the muscular and serous coats of the intestine and the abdominal parietes on each side, so as to thoroughly secure it from slipping. Finally, the spur of intestine, about three inches long, which is left protruding from the wound, is packed carefully round with thymol gauze, the whole covered with a thick pad of cotton-wool and a many-tailed flannel bandage lightly applied. The dressings should not be disturbed for three or four days unless symptoms occur necessitating their removal. On the fourth or fifth day the spur may be cut away on a level with the skin, all bleeding points secured, and the wound dressed with eucalyptus or boracic ointment. One great trouble to be feared in Allingham's operation, and the one I am describing, is the tendency of retraction of the stirrup of intestine when the loop or spur is cut off. I therefore in future shall content myself with opening the spur on the fourth or fifth day, and delay its total removal until some days later. This would have the further advantage of enabling the wound to be kept quite free from contamination from the escaping fæces

$$
\text { I am, Sirs, yours faithfully, }
$$

Fred. Bow Reman JessetT.

Upper Wimpole-street, December, 1889

\section{DR. RENTOUL'S SCHEME.} To the Editors of THE LANCET.

Srrs, - As chairman of the meeting at Bethlem Huspital, referred to in Mr. R. H. S. Carpenter's letter in your last issue, I shall be glad if you will allow me to make some rernarks in answer. Mr. Carpenter is mistaken on one or two points. The meeting was one of the South London District of the Metropolitan Counties Branch of the British Medical Association, and was summoned at the instance of the conmittee of that district for the purpose of obtaining the opinion of members of the district on the proposal of Dr. Rentoul, a course which was subsequently approved by a meeting of the council of the branch. On this occasion no general invitation was issued to the practitioners of the south of London.

The members of the Association were not ontnumbered by visitors. There were seventeen members present, including the chairman and secretary, and only seven whose names are not on the list of the Branch. In reference to the proceedings, I can only say that, as chairman, I was bound by the rules of the district, one of which is to the effect that the chairman shall invite all visitors to express their opinions; but another prohibits voting by any but members of the Branch. It would clearly be against the spirit of that rule to allow any visitor to propose a resolution which he could not support by a vote. Such regulations do not seem to me peculiar to the British Medical Association. No Society or Association could allow its visitors-however free to speak - to vote, and thus control the action of that Society. But I can assure Mr. Carpenter that there was no attempt to hoax anyone, and I quite fail to see how the meeting can be so regarded. I am, sirs, yours faithfully,

FREDERICK TAYLOR,

Vice-President of the South London District.

St. Themas's-street, S.E., Nov. 30th, 1889.

\section{To the Editors of THE LANCET.}

SIRs, - The meeting at Bethlem Hospital on Nov. 13th to which Mr. Carpenter refers was a meeting of the South London District and not of the whole Metropolitan Branch, as might be inferred from Mr. Carpenter's letter. As mover of the amendment in favour of Dr. Rentoul's proposals, I wish to point out that it was by no means in the interests of our party that the voting was restricted to members of this Branch of the Association. The chairman and secretary, who both opposed Dr. Rentoul's proposals, were responsible for the enforcing of this bye-law of the Branch. For my own part, I thought that it would have been in better taste if the chairman had left this rule in abeyance in case no member insisted upon it. Mr. Carpenter must remember that a bye-law of the Metropolitan Branch, while allowing visitors to join in the discussions, forbids their voting.

As a special meeting of the whole Metropolitan Branch will shortly be held, and as the same rule is liable to be enforced, I would suggest that the above bye-law should be left in abeyance. I think I can say that there will be no objection to this on behalf of Dr. Rentoul's supporters. As a matter of fact, if anyone present at these meetings chooses to vote, there are never, so far as I know, any steps taken to test the right to do so. No doubt the proposer and seconder of a resolution run the risk of being challenged; and it is certainly irregular for anyone but a member to vote.

As to Mr. Carpenter's sneer at the officials of the British Medical Association, I beg to remind him that they have no power to set aside existing rules of the Association. I am, Sirs, yours faithfully,

Highgate, N., Nov. 30th, 1889. HUGH WoODs, M.D.

\section{THE PATHOLOGY OF CHOREA.}

\section{To the Editors of THE LANCET.}

SIRs, - I trust that you will allow me to reply briefly to some of the criticisms of Dr. Maclagan upon the paper in which I suggested that the clinical associations of chorea point to the possibility of its origin in some temporary overgrowth of connective tissue in the nerve centres. Dr. Maclagan asks what evidence there is that rheumatism is capable of producing increased growth of connective tissue. Of its power of doing so I would quote the subcutaneous rheumatic nodules as standing examples, for they have been repeatedly shown to consist of connective tissue in a state of active growth. Dr. Maclagan adds that few pathologists are likely to endorse the view that the lesions of endocarditis are analogous with those which result in nodule formation yet this view is supported by the results of microscopic research, and since it was first enunciated by Drs. Barlow and Warner in 1881 has gained wide acceptance. Nor can I see that it is in any way disproved by the so frequent limitation of the endocardial process to the valves, and to certain portions thereof ; for although, with all respect to the opinion of Dr. Maclagan, I am not prepared to agree entirely with his views as to the influence of strain, I should be the last to deny that mechanical influences play a very important part in determining the distribution and seat of rheumatic lesions either in the joints or heart. If the clue to the association of chorea with rheumatism lies in the fact that one is a disease of the motor apparatus, the other of the motor centres, we might surely expect to 
trace a similar association of chorea with gout and rheunatoid arthritis, in spite of the rarity of these maladies in early life. Unquestionably the undoubted occurrence of nonrheumatic chorea offers a very serious objection to the hypothesis suggested in my paper, if it can be shown that temporary fibrous tissue overgrowth is pathognomonic of rheumatism; but I do not think that it is proved that similar changes are not produced in other diseases, even although they may not result in the formation of subcu. taneous nodules in the characteristic situations. In conclusion, I may say that I would not for a moment deny that the hypothesis at present rests upon slender foundations, but I believe that the clinical considerations upon which it is based warrant the suggestion of a line of pathological research.

I am, Sirs, yours faithfully,

Chandos-street, W., Dec. 2nd, 1889.

ARCH. E. GARROD.

\section{"MEAN DURATION OF LTFE."}

\section{To the Editors of THE LANCET.}

SiRs,-Parkes gives the following formula for calculating the mean duration of life, and at the same time condemns this quantity as a test of the health of the population considered: $\frac{2}{3}$ inverse of death-rate $+\frac{1}{3}$ inverse of birth-rate. This, when the birth-rate equals the deathrate, coincides with the formula quoted by Mr. S. C. Waters-viz, the inverse of the death-rate. The figures in Dr. Corfield's report do not agree with either of these formula, so that, as he asserts that he gives the real average duration of life walculated from the death-rate of his district, and not, as you suggested, the average age at death, it would be interesting to know the method used by him. The expression "mean duration of life" is, I hear, avoided by actuaries, but much affected by political and social orators and writers. Nothing puts an audience into a better frame of mind than telling them the mean duration of life has been increased. it is taken to mean, as Mr. Waters suggests, the expectation at birth, it is essentially yearless, and quite unfit to be employed as a test of health in any particular year. I think two things are necessary in the proper use of figures: that they should be correctly used, and also that no attempt should be made to claim for them a greater precision than the subject admits of. The death-rate itself is acknowledged to be simply a convenient expression for something that gives a rough indication of the health of a district, and any figures arrived at from this basis by means of an approximate formula must be very wide of the mark. The true statement of the case is this. The reciprocal of its deathrate is roughly proportional to the state of health of a district, and is therefore roughly proportional to the dura tion of life in that district, generally speaking. The expression " mean duration of life" applied to any particular year is scientifically meaningless and misleading to the public. I am, Sirs, yours faithfully,

Dec. 1889 T. Glover Lyon, M.A., M.D. Cantab.

\section{"BLINDNESS BY DISABILITY." \\ To the Editors of THE LANCET.}

SIRs,--You will doubtless be deluged with letters on the subject of Dr. Gowers' communication in your last edition. Dr. Gowers, who is a consummate master of that most difficult instrument, the ophthalmoscope, warmly mentions a case of optic neuritis in chlorosis which, unfortunately, was under the care of a medical man unable to use the ophthalmoscope, and terminated ultimately in blindness. It was a sad case, certainly, and it would appear that the medical attendant was greatly to blame, not in my opinion so much on account of his ignorance of the ophthalmoscope as because he failed to properly treat the chlorosis, the cause of the neuritis, with its suitable and well-known remedy-viz., iron. All physicians and surgeons who specially study the eye and its diseases must every now and then come across the unhappy results of ignorance and incompetence, and I wonder what Dr. Gowers would say to the case of a poor fellow, only forty-seven, who came to see me a few weeks back, totally blind in his left eye, and with the following history. About two years ao o he was admitted into a hospital suffering from some form of ulceration of the leg, and whilst in this institution an attack of typical acute glaucoma came on in his left eye, with severe pain and vomiting, and rapid loss of vision; no operation, he tells me, was ever suggested to him, the eye was treated with "lotion, drops, and caustic," and seven weeks from the onset of his attack he left the hospital with the sight of that eye completely gone, and when I saw him it was in a state of glaucoma absolutum, with the typical glaucoma cup, and to make matters worse, he is suffering from an old injury to his other eye, the sight of which is letters of $20 \mathrm{~J}$ aeger slowly. In my innocence I had thought that every medical man knew of the existence of acute glaucoma, and that iridectomy, done in time, is an absolute specific for it. But Dr. Gowers refers to a wider subjectthe instruction in the use of the ophthalmoscope given at the schools, and the number of the men who avail themselves of it. And here I think there is good cause for congratulation. I can myself speak for two schools. Eleven years ago I finished my hospital career in London, having, amongst other prizes, taken the medal for Practical Medicine, and I can safely say I never saw the optic disc all the time indeed, the student who even possessed such a thing as an ophthalmoscope was a rura avis. It was not con sidered the thing to go into the Eye Department, and I never felt welcome there myself; one always seemed to be intruding, at least so I thought. Later I studied at Edinburgh University, and graduated there, dividing with another the prize given to the most distinguished graduate, and yet, $I$ believe, only on one occasion had I succeeded in catching a hurried glimpse of the optic disc. I mention these facts, not in personal agorandisement, to show that only a few years ago it was possible to take the highest prizes at two large schools of medicine without being able to recognise an optic disc; yes, or the vocal cords or mem. brana tympani either. I have fortunately been able to rectify those defects, and, returning and working at both my former places of study under a new régime, I am surprised to find the number of men with a very competent. knowledge of the ocular fundus, and it would be impossible, I believe, now to take a prize for medicine at either institution without a good knowledge of the ophthalmoscope, and doubtless, ere very long, men will be unable to graduate at any university in the United Kingdom without being able to diagnose the various common diseases of the fundus of the eye. I am, sirs, yours obediently,

Norwich, Nov, 25th, 1889 .

$$
\text { S. JOHNSON TAYLOR, M.B., M.R.C.S. }
$$

\section{THE MORTON LECTURE ON CANCER.}

\section{To the Editors of THE LAANCET.}

SIrs,--I am pleased to find that Dr. Inglis Parsons hass reason to think that his operation may be effective at fewer sittings than I supposed, or even at a single sitting. I am quite satisfied that he has been before me in publishing the opinion that cancer cells escape the control of the nervous system, for I have never published any of my views on cancer; but that these latter are entirely independent, and, more than that, may turn out to be incorrect, is what $I$ am equally ready to maintain. I will explain my views, and the processes by which $I$ arrived at them, in a note to the Morton Lecture, when this is published.

I am, Sirs, yours truly,

Savile-row, W., Dec. 2nd, 1889. John Marsifali.

\section{OPERATIVE TREATMENT OF FLAT-FOOT.}

To the Editors of THE LANCET.

SIRs,-It has been strongly urged upon me that, if I still hold osteotomies for flat-foot to be unwarranted, because unnecessary, I ought not to allow Mr. Hare's paper in THE LANCET of Nov. 16th to pass unnoticed. But I have felt, as I did on reading Mr. Davy's communication to the Medical Society in March last, that if the facts and considerations which, during the past six years, I have repeatedly laid before your readers have not convinced, neither would anything for which I could reasonably ask you to spare me space be likely to do so now. Moreover, have recently stated at full length, in a published book, my views on the physiology of the feet. Therein I have attempted to prove, among other propositions, these, which I first propounded more than sixteen years ago:-1. The muscles that by their action move the foot and the body upon it, in their action support the arch, which, in early life, they develop. 2. Flat-foot is due to failure of this functional support; renewal of functions in specially active manner will restore the arch. As, however, in my book I 